\title{
Tükrük bezi hastalıklarında kullanılan tanı yöntemleri arasında sialendoskopi de düşünülmelidir.
}

\section{Sialendoscopy should also be considered in the diagnosis of salivary gland diseases}

1 Medical Park Hastanesi Kulak Burun Boğaz Kliniği, Tokat, Türkiye

\section{Corresponding Author:}

Op. Dr Dr Zeki Sezgin

Medical Park Hastanesi

Kulak Burun Boğaz Kliniği, Tokat, Türkiye

Email:

sezginz@yahoo.com.tr

Başvuru Tarihi/Received :

23-10-2016

Kabul Tarihi/Accepted:

17-11-2016

\section{Zeki Sezgin $^{1}$}

\section{Sayın Editör,}

Çağdaş Tıp Dergisi'nde 2011 yılının Cilt 1 Sayı 2'de yayınlanan Akdağ ve ark. na ait 'Tükrük bezi hastalıklarında kullanılan tanı yöntemlerinin değerlendirilmesi' orijinal makalesini ilgi ile okuduk ve çok değerli bulduk. Tükrük bezi hastalığı olan 50 olgu üzerinde yapılan söz konusu çalışmada tüm hastalara tanı maksatlı ultrasonografi, siyalografi, bilgisayarlı tomografi ve ince iğne aspirasyon biobsisi uygulanmıș ve bu tetkiklerin tanı koymadaki yararları araştırılmıştır ${ }^{1}$. Biz de katkı olarak tükrük bezi hastalıklarında güncel bir yöntem olan diagnostik maksatlı sialendoskopiden bahsedip katkı da bulunmak istiyoruz.

Sialendoskopi majör tükrük bezi kanallarını ve patolojilerini direkt görüş ile değerlendirmeye yarayan, düşük morbiditeli, yeni bir yöntemdir. Ana kanal, ikincil ve üçüncül kanalların endoskopik bakısıla, hekime darlıklar, mukus tıkaçları, polipler ve taşlar arasında ayırıcı tanı imkânı sağlar².

Sialendoskopinin kullanıma girmesiyle tükrük bezinin nonneoplastik hastalıklarının tedavisinde bir paradigma kaymasına sebep olmuştur. $\mathrm{Bu}$ minimal invaziv teknik; tükrük bezi kanallarının değerlendirilmesi için fleksibl endoskop kullanan Katz ve Fritz tarafindan ilk olarak 1990‘l1 y1llarda tanımlanmıştır ${ }^{3}$.

Sialendoskopinin temel endikasyonu tükrük bezlerinin orijini belli olmayan tüm intermittant şişlikleridir ${ }^{4}$.

Diğer endikasyonları ${ }^{5}$;

1. Occult tükrük bezi taşlarının tanısı

2. Mukus veya fibrin tıkaçlar gibi taş oluşumunun erken formasyonlarını ortaya koyma ve taş oluşumunun proflaksisi

3. Postinflamatuar stenoz ve diğer obstrüktif durumların tanısı ve tedavisi

4. Anatomik varyasyonlar ve malformasyonların tanı ve tedavisi

5. Tükrük bezlerini tutan otoimmün hastalıkların nedenleri olarak yeni bakış açısı ve teşhisi

6. Tedavi başarı oranlarının kontrol ve takibi 
Ayrıca juvenil recurrent parotitis de altta yatan patolojiyi anlamamıza yardım eder. Çünkü bu hastalık pediatrik yaş grubunda parotis glandı etkileyen ve etyolojisi bilinmeyen rekürren bir enflamasyondur.

Aynı zamanda bu hastalıkta sistemik olarak kullanılan steroidler bir prob yardımı ile direkt olarak arzu edilen yere verilebilmekte ve steroidin etkinliğini artırıp sistemik yan etkilerinden korumaktadır ${ }^{6}$.

Tükrük bezi hastalıklarında kullanılan sialografi değerli bilgiler vermekle beraber sadece kanal obstrüksiyonunu gösterir. Ayırıcı tanıya yardımcı olmaz ve yüksek dozda radyasyon gerektirir ${ }^{2,7}$. Direkt grafilerin taşlar için spesifitesi $\% 60-80, \mathrm{MR}$ sialografinin ise $\% 98 \mathrm{dir}^{2,8}$. Ultrasonografide ise $2 \mathrm{~mm}$ ve üzerindeki taşlar görülebilir ve başarı oranı \% 80-94'dür.

Marshal ve arkadaşları şüpheli kanal hastalığı ve şişliği olan 135 submandibular gland da diagnostik sialendoskopinin başarı oranını \% 97 olarak bulmuşlar ve hiçbir komplikasyonla karşılaşmamışlardır. Tanılar \%74,1 taş, $\% 10,5$ sialodochitis, $\% 5$ stenoz ve $\% 9.8$ normal kanal olarak bildirmişlerdir ${ }^{9}$. Parotis glandda yaptıkları 79 vakalık başka bir çalışmada ise sialendoskopilerin tamamını başarılı bildirmişler ve burada da komplikasyonla karşılaşmamışlardır. Tanılar ise \% 66 taş, $\% 39$ sialodochitis, $\% 8$ darlık ve $\% 16$ normal kanal olarak bildirmişlertir ${ }^{10}$.

Şerbetçi ve arkadaşlarının 2010'da Türkiye'de yaptıkları majör tükrük bezlerinde duktal obstrüksiyonla başvuran hastalarda 60 gland üzerine yaptıkları sialendoskopik bir çalışmada 38 glandda taş, 15 glandda stenoz,3 glandda sineşi ve bir glandda kink formasyonu tespit etmişlerdir. Ayrıca 21 mukus tıkaçı, 4 duktal ektazi, 1 polip ve 1 duktal kollaps da diğer patolajilerin yanında eşlik ettiğini bildirmişlerdirr ${ }^{11}$.

Sonuç olarak diagnostik sialedoskopi tükrük bezi kanal hastalığını değerlendiren düşük morbiditeye sahip yeni bir tekniktir. Terapötik sialendoskopi ise açık gland eksizyonunu önleyen ve çoğu hastada taşın çıkarılmasını ve darlığın giderilmesini mümkün kılan bir müdahaledir ${ }^{10}$.Ancak tükrük bezi patolojilerinin tedavisinde tedavi maksatlı yeni minyatürize enstrumanların geliştirilmesi ve optik rezolüsyonun arttırılmasıyla sialendoskopinin etkinliği arttırılmalıdır.

\section{Kaynaklar}

1. Akdağ M, Müderris S. The evaluation of diagnostic methods used in salivary gland diseases. Journal of Contemporary Medicine 2011; 1 (2):50-55

2. Hopf JUG, Hopf M, Gundlach P, Scherer H. Miniature endoscopes in otorhinolaryngologic applications. Min Invas Ther \& Allied Technol 1998;7/3:209-18.

3. 4. Katz P, Fritsch MH. Salivary stones: innovative techniques in diagnosis and treatment. Curr Opin Otolaryngol Head Neck Surg. 2003;11:173-178. doi: 10.1097/00020840-200306000-00008. [PubMed][Cross Ref]

4. Marchal F, Dulguerov P, Becker M, Lehmann W. Interventional sialendoscopy. In: Wackym PA, Rice DH, Schaefer SD, editors. Minimally invasive surgery of the head, neck and cranial base. Philadelphia: Lipincott Williams \& Wilkins, 2001.

5. Koch M, Zenk J, Bozzato A, Bumm K, Iro H. Sialoscopy in cases of unclear swelling of the major salivary glands. Otolaryngol Head Neck Surg 2005; 133: 863-8

6. Curr Opin Otolaryngol Head Neck Surg . 2016 Sep 15. DOI: 10.1097/MOO.0000000000000314

7. Marchal F, Dulguerov P, Lehmann W. Interventional sialendoscopy.N Engl J Med. 1999 Oct 14;341(16):1242-3.

8. Kalinowski M, Heverhagen JT, Rehberg E, Klose KJ, Wagner HJ. Comparative Study of MR Sialography and Digital Subtraction Sialography for Benign Salivary Gland Disorders. Am J Neuroradiol 2002 Oct; 23(9):1485-92. 12372736

9. Marchal F, Dulguerov P, Becker M, Barki G, Disant F, Lehmann W. Submandibular diagnostic and interventional sialendoscopy: new procedure for ductal disorders.Ann Otol Rhinol Laryngol. 2002 Jan;111(1):27-35. 11800367

10. Marchal F, Dulguerov P, Becker M, Barki G, Disant F, Lehmann W. Specificity of parotid

sialendoscopy.Laryngoscope. 2001 Feb;111(2):264-71. 11210873

11. Şerbetçi E,Şengör AG,Sialendoscopy:Experience with the first 60 glands inTurkey and a literature review.Ann Otol Rhinol laryngol.2010.119(3):155-164 